\title{
EDITORIAL
}

\section{Carers as partners in care ${ }^{1}$}

\author{
Nick Hervey \& Rosalind Ramsay
}

The initial impact of the Carers (Recognition and Services) Act 1995 was limited, but it did mark the start of a gradual shift in the way mental health professionals perceive carers. Further government initiatives followed. In 1999, Standard 6 of the National Service Framework (NSF) for Mental Health introduced the requirement that professionals assess the needs of every carer of an individual receiving enhanced aftercare under the care programme approach. Other policy documents have continued to promote the need to include carers in planning the aftercare of mental health service users. Under Section 11 of the Health and Social Care Act 2001, strategic health authorities, primary care trusts and National Health Service (NHS) trusts are now required to make arrangements to involve and consult patients and the public. Of necessity, the latter will include carers, who, as members of the public, have a specific interest in the quality of service provision. Amendments to the Local Government Act 2000 have given local authorities the power to 'advance the social, economic and environmental well being of the communities they serve'.

\section{Changing the prevailing culture}

The UK's 6 million carers save the Government $£ 57$ billion a year in potential care costs (Carers UK, 2002). This in itself presents a compelling reason for supporting carers, and yet many staff continue to focus on service users alone, ignoring the care networks that support them. In 2003 one of us (N.H.) analysed local carers' needs assessments in the London borough of Southwark. Carers reported visiting in-patient units and being ignored, being starved of information and being omitted from full participation in aftercare planning.

1. See Livingstone \& Cooper, pp. 85-92, this issue.
On a wider stage, the Patient and Public Involvement agenda has highlighted that many NHS trusts still fail to consult effectively with local people. In 2000, the Local Government Act gave local authorities responsibility for monitoring health organisations in their area. Subsequently, amendment to legislation in the Health and Social Care Act 2001 required them to set up 'overview and scrutiny committees' led by a constitutionally elected member of the local authority council. Section 11 of the Health and Social Care Act also laid a duty on trusts to notify the local authority of any 'substantial developments or variations' to services, and has required the chief executives of trusts to attend overview and scrutiny committee meetings and provide information to them about health activity as and when required.

The NHS Reform and Health Care Professions Act 2002 has put the latest elements of the Patient and Public Involvement agenda in place, by providing for a Commission for Patient and Public Involvement in Health (CPPIH), setting up both patients' forums that carers can apply to join and independent complaints and advocacy services (ICAS). Encouraging carers to become involved in these wider activities and services will ensure that the debate is informed by members of the public with a specific knowledge of the issues.

In order to effect real change there needs to be a shift in the prevailing culture to one in which carers are seen by professionals as partners in promoting the care of service users - as partners with real knowledge and a unique perspective to contribute. This means finding innovative ways of involving carers in the care system and, where necessary, paying them for their involvement.

In order to effect real change there needs to be a shift in the prevailing culture towards one in which carers are seen by professionals as partners in promoting the care of service users - as partners with real knowledge and a unique perspective to contribute. This means thinking through innovative

Nick Hervey is a social worker by profession and Head of Social Care in Southwark Mental Health Services. He is a co-editor of Collaborative Community Mental Health Care (Ritter et al, 1995). He has a PhD in the history of psychiatry and is a coauthor of Masters of Bedlam (Scull et al, 2000). Rosalind Ramsay is an adult consultant psychiatrist with South London and Maudsley NHS Trust (Maudsley Hospital, London SE5 8AZ, UK) and has an interest in mental health services. She is a member of the Public Education Committee and in 2001 edited Mental Illness: A Handbook for Carers. 
ways of involving carers in the care system and, where necessary, paying them for their involvement.

In many respects the same principles apply to our thinking about how we can involve local voluntarysector agencies, to many of which carers belong, in a more fruitful partnership. In 1998 the Government introduced the Compact, a code of good practice to govern its work with the voluntary and community sector (Department of Health, 2003). Since that time local authorities have been developing 'local compacts' for partnership working with their own voluntary sector, and local trusts are expected to sign up to the principles in these. The latter include a greater emphasis on transparent consultation processes, real support for volunteers and effective communication with Black and minority ethnic community organisations. Once again this should mean more effective opportunities for carers to be involved in the local delivery of services.

Figure 1 provides a diagrammatic representation of the above changes, separating out the local authority, NHS-managed bodies and independent advocacy/representative systems.

What, then, is it that carers want? The most consistent finding from analysis of aggregated local carers' assessments is that carers desperately want information - information about services, diagnosis, treatment options and support mechanisms. They also want recognition of what they do. Often they feel caught in a lonely struggle in which they are undervalued and isolated from their surrounding community, ostracised by association with a person who is not mentally well. If parents, they are struggling with their feelings about the lost hopes they had had for their child; if sons and daughters, they are mourning for the supportive parent they no longer have. In the Black community these feelings of isolation and loss may be compounded by a fear of mental health services, which means that carers do not seek help until a problem has reached crisis level. Thus, many carers are also seeking reassurance that services are culturally appropriate and that staff will welcome their involvement (Sainsbury Centre for Mental Health, 2002: p. 43).

\section{Good service models}

The NSF for Mental Health, which gives examples of good practice for each of the standards, has little to say about good practice around work with carers. However, there are some local initiatives that are beginning to alter the balance of power in relation to the care system supporting an individual patient. The NSF for Mental Health highlighted Rethink's Carers' Education and Support Package programme,

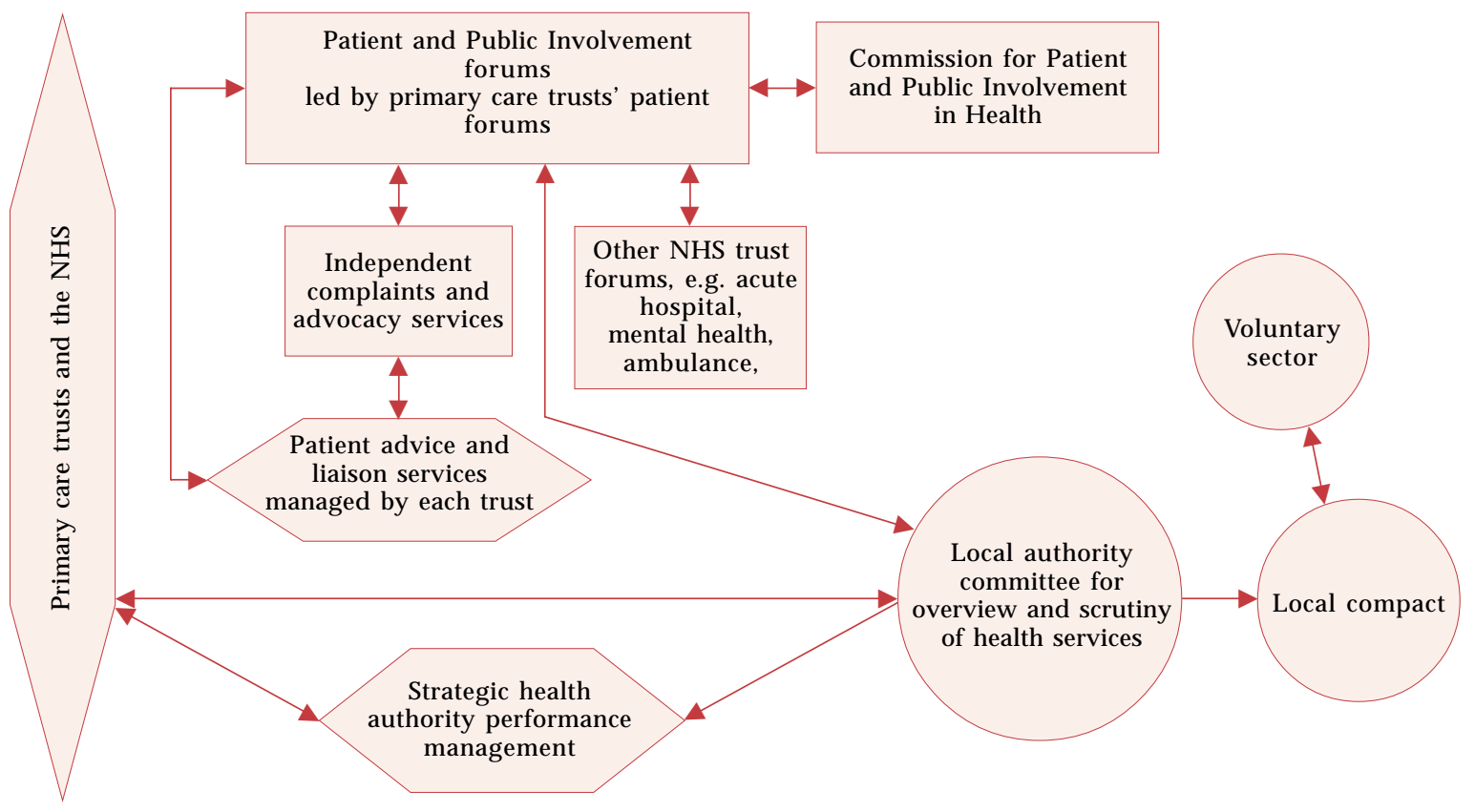

Fig. 1 Patient and public involvement structures. Rectangles show independent agencies that support patient and public involvement within the health system by offering information and advice; circles indicate local authority systems for scrutinising health and work within the volunary sector; and polygons show the NHSmanaged bodies involved (after Department of Health Directorate of User Experience and Involvement, PPI Workstream, 2003: p. 62) 
which has been influential in places where it has been implemented. In each new programme, a carer who has already been trained helps to support the next training set. Gradually this is building up a cadre of expert carers who are able to influence local practice, deliver training to staff and run support groups for other carers.

Many areas have set up carers' steering groups, which can provide an overview of carer activity and support staff from different service areas in promoting carer involvement in their workplace. There are many things that staff can do locally, such as running open carers' evenings where information is made available and staff can talk with carers. Some areas have developed carers' crisis cards, which list important contact numbers, and also specific information packs for carers. In many local authorities, mental health partnership boards now have carer representation, and where these representatives are elected from a strong carer base they are able to provide more effective input to planning and developing services.

In the past, carer involvement usually related to an individual service user, but increasingly we need to think about carers having a wider role in services. This may not apply to all carers, as indeed user involvement does not suit all users, but carer involvement provides a unique perspective, and most staff benefit from developing a more positive link with carers.

With the advent of Patient and Public Involvement, trusts and local mental health partnership boards have started to run regular stakeholder events, and it is essential that these are well publicised so that carers can give their views. Currently, for example, many trusts are planning to form 'early-onset' services, in line with the NSF's requirements. Clearly, the carers of young people with an earlyonset illness have a huge interest or stake in how these services are set up and managed. Another example would be the creation of assertive outreach teams.

Recently, a number of influential policy documents have highlighted concerns about the high levels of recorded mental illness in the Black community. Breaking the Circles of Fear (Sainsbury Centre for Mental Health, 2002), Inside, Outside (National Institute for Mental Health in England, 2003) and the Government's race equality strategy (Department of Health, 2003a) have illustrated how Black carers avoid the statutory care systems and try to contain problems in their community long beyond the point at which one would expect them to seek help. In the London borough of Southwark, the Cares of Life project is trying to engage the community in a much wider programme of involvement. The aim is to build a gateway organisation with roots in the local Black community and to recruit a range of staff and volunteers who can work with local churches, Black businesses, barber shops and voluntary sector organisations to build bridges to primary care and secondary mental health services. Another aim is to increase social capital in the area and to provide the community with mechanisms for supporting those of its members who have more common mental health problems ('cares of life'), thus minimising the number of people who need to enter secondary mental health services. A key element of the scheme is a local 'time bank', where users and carers can volunteer their time (in 1-hour credits) and, having banked some hours, can receive the help they need from people with other skills. This is a new way in which carers can become involved in supporting a relative or friend.

An area of current research is the sharing of information between professionals and carers (http://www.mentalhealthcare.org.uk/surveys / informationsharing). The Department of Health gives the following brief guidance on disclosing information to carers who do not have parental responsibility for the service user:

'Carers often provide valuable healthcare and every effort should be made to support and facilitate this work. Only information essential to the patient's care should be disclosed and patients should be made aware that this is the case. However, the explicit consent of a competent patient is needed before disclosing information to a carer. The best interests of a patient who is not competent to consent may warrant disclosure' Department of Health (2003b).

Discussing family involvement in the care of people with a psychotic illness, Szmukler \& Bloch (1997) put forward a number of grounds for overriding a patient's refusal, which are summarised in Box 1. Questions about the duty of care that mental health professionals owe towards carers over and above those that they owe to their patients are still to be explored.

Box 1 Grounds for overriding a patient's refusal to disclose information to family (after Szmukler \& Bloch, 1997)

- If the harms to be avoided are serious

- If there are no available alternative options

- If the family's pre-existing values embody mutual concern and support

- If not involving the family could lead to greater restrictions on the patient's liberty

- If there is impairment in the patient's capacity to make a genuine choice 


\section{References}

Department of Health (2003) Compact. A Dynamic Mechanism for an Evolving Relationship with the Voluntary and Community Sector. London: Department of Health. http://www.thecompact.org.uk/

Department of Health (2003a) Delivering Race Equality. A Framework for Action (consultation document). London: Department of Health.

Department of Health (2003b) Confidentiality: NHS Code of Practice. London: Department of Health.

Department of Health Directorate of User Experience and Involvement, PPI Workstream (2003) A Guide to the NHS for Members and Officers of Health Scrutiny Committees. London: Department of Health. http://www.doh.gov.uk/ involvingpatients/guidance.htm

National Institute for Mental Health in England (2003) Inside Outside: Improving Mental Health Services for Black and Minority Ethnic Communities. Leeds: Department of Health
Carers UK (2002) Adding Value: Carers as Drivers of Social Change. London: Carers UK.

Ritter, S., Watkins, M., Carson, J., et al (1995) Collaborative Community Mental Health Care. London: Hodder Arnold.

Scull, A., MacKenzie, C. \& Hervey, N. (2000) Masters of Bedlam. The Transformation of the Mad-doctoring Trade. Princeton, NJ: Princeton University Press.

Livingston, G. \& Cooper, C. (2004) User and carer involvement in mental health training. Advances in Psychiatric Treatment, 10, 84-91.

Ramsay, R. (ed.) (2001) Mental Illness: A Handbook for Carers. London: Jessica Kingsley.

Sainsbury Centre for Mental Health (2002) Breaking the Circles of Fear. A Review of the Relationship between Mental Health Services and the African and Caribbean Communities. London: Sainsbury Centre for Mental Health.

Szmukler, G. \& Bloch, S. (1997) Family involvement in the care of people with psychoses. An ethical argument. British Journal of Psychiatry, 171, 401-405.

\section{NEW TRAINING VIDEO - FROM THE COLLEGE'S PARTNERS IN CARECAMPAIGN}

\section{Being Seen and Heard \\ The Needs of Children of Parents with Mental IIIness \\ By Dr Alan Cooklin}

Children with a parent with mental illness often fall through the professional net and are seen as nobody's responsibility. Nothing is explained to them, and they often receive no help at all to deal with the effects of the parent's illness. These children need to be seen and heard.

As many as 175000 young people in the UK are involved in the care of an adult with mental illness. These children usually worry about their parents, may blame themselves for the illness, fear that they will 'catch' the illness and feel unsupported.

All professionals working with adults with mental illness need to stop and think about the needs of these young people. This training package provides practical and creative suggestions about working with children and parents. It contains clips of children, young people and their parents talking about their experiences of mental illness and

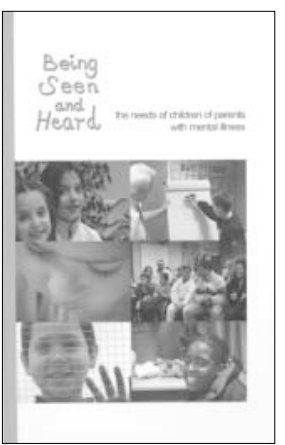
how professionals can work effectively with them.

January 2004, 1-hour video plus CD-ROM, ISBN 1904671 10 1, Price £35.25 (incl. VAT)

NOW AVAILABLE FRO M:
Book Sales, Royal College of Psychiatrists, 17 Belgrave Square, London SW 1X 8PG, UK.
Tel: +44 (0)20 7235 2351 ext 146. Fax: + 44 (0)20 7245 1231.
Order online: ww w.rcpsych.ac.uk/publications

